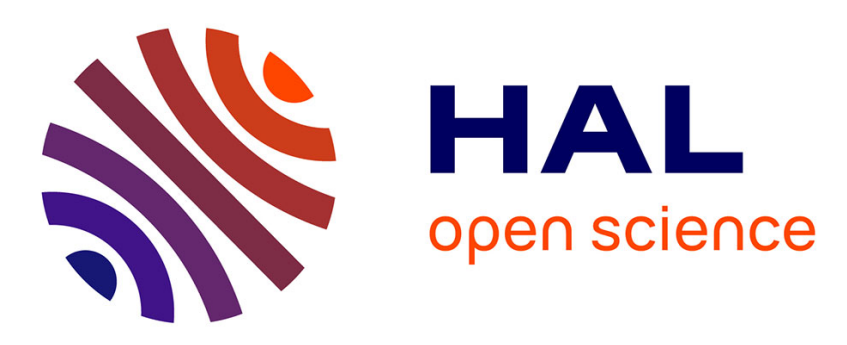

\title{
A phase-I trial of pemetrexed plus carboplatin in recurrent ovarian cancer
}

Jalid Sehouli, Oumar Camara, Sven Mahner, Thomas Bauknecht, Werner

Lichtenegger, Ingo Runnebaum, Katherine Look, Fritz Jaenicke, Guelten

Oskay-Oezcelik

\section{To cite this version:}

Jalid Sehouli, Oumar Camara, Sven Mahner, Thomas Bauknecht, Werner Lichtenegger, et al.. A phase-I trial of pemetrexed plus carboplatin in recurrent ovarian cancer. Cancer Chemotherapy and Pharmacology, 2010, 66 (5), pp.861-868. 10.1007/s00280-009-1230-3 . hal-00568279

\section{HAL Id: hal-00568279 \\ https://hal.science/hal-00568279}

Submitted on 23 Feb 2011

HAL is a multi-disciplinary open access archive for the deposit and dissemination of scientific research documents, whether they are published or not. The documents may come from teaching and research institutions in France or abroad, or from public or private research centers.
L'archive ouverte pluridisciplinaire HAL, est destinée au dépôt et à la diffusion de documents scientifiques de niveau recherche, publiés ou non, émanant des établissements d'enseignement et de recherche français ou étrangers, des laboratoires publics ou privés. 


\section{A phase I trial of pemetrexed plus carboplatin in recurrent ovarian cancer}

Jalid Sehouli ${ }^{1}$, Oumar Camara ${ }^{2}$, Sven Mahner ${ }^{3}$, Thomas Bauknecht ${ }^{4}$, Werner Lichtenegger ${ }^{1}$, Ingo Runnebaum ${ }^{2}$, Katherine Look ${ }^{5}$, Fritz Jaenicke ${ }^{3}$ and

Guelten Oskay-Oezcelik ${ }^{1}$

on behalf of the NOGGO Study Group Ovarian Cancer

${ }^{1}$ Dept. of Obstetrics and Gynecology, Charité University Hospital, Campus Virchow, Berlin, Germany

${ }^{2}$ Dept. of Obstetrics and Gynecology, Friedrich Schiller University of Jena, Jena, Germany

${ }^{3}$ Dept. of Gynecology, University Medical Center Hamburg-Eppendorf, Hamburg, Germany

${ }^{4}$ Medical Department Oncology, Lilly Deutschland GmbH, Bad Homburg, Germany

${ }^{5}$ Medical Department Oncology, Eli Lilly and Company, Indianapolis, USA

\section{Corresponding author:}

Jalid Sehouli, MD, Professor

Dept. of Obstetrics and Gynecology

Charité University Hospital, Campus Virchow-Clinic

13353 Berlin, Germany

Tel: +49-30-450 564052

Fax: +49-30-450 564952

email: sehouli@aol.com

Running title: pemetrexed and carboplatin in ovarian cancer phase 1

Article Type: Original Article

Research Support: Lilly GmbH

Key words: recurrent ovarian cancer; pemetrexed, carboplatin; second-line treatment 
Summary

Background:

Carboplatin-based combinations are established in platinum-sensitive recurrent ovarian cancer. To improve the therapeutic-index, new platinum-based combinations are required. Pemetrexed is a multi-targeted antifolate inhibiting thymidylate-synthase. The aim of this study was to determine the maximally tolerated dose (MTD) and dose limiting toxicity (DLT) and to characterize toxicities of the combination of pemetrexed (Pem) and carboplatin $(\mathrm{Cb})$. Design:

A standard 3-patient cohort dose-escalation was performed starting at $\mathrm{Cb}$ AUC-5 and Pem $500 \mathrm{mg} / \mathrm{m}^{2}$. Patients with platinum-sensitive recurrent ovarian cancer were eligible. Two levels of $\mathrm{Cb}(\mathrm{AUC}-5,6)$ and five levels of Pem $\left(500,600,700,800,900 \mathrm{mg} / \mathrm{m}^{2}\right)$ were evaluated. DLTs were based on cycle 1.

Results:

Twenty patients were enrolled. The median age was 57.4 years (37.3-75.3) and the median platinum-free interval was 26.2 months (7.2-124.4). There was one DLT at dose-level 3 in cycle one. No serious adverse events related to the study therapy were observed. The 20 patients completed 112 cycles of $\mathrm{Cb}$ (104 were planned) and 115 cycles of Pem (112 were planned). The maximum dose level of Cb AUC-6 and Pem 900 mg/m² was well tolerated. Response rates in 19 patients were: CR: $63.2 \%$; PR: $21.1 \%$; SD; $5.3 \%$, PD: $10.5 \%$. Conclusions:

The combination carboplatin and pemetrexed is safe and well tolerated. A multicenter phaseII trial is currently underway. 


\section{Background}

Epithelial ovarian cancer is the leading cause of death from gynecological malignancies world-wide [1]. Most patients were present with advanced disease at the initial diagnosis. Current standard management of primary ovarian cancer includes radical cytoreductive surgery followed by systemic chemotherapy with carboplatin plus paclitaxel. More than 65\% of the patients with advanced ovarian cancer will relapse and require additional treatment [2]. Retrospective studies have identified two subgroups of patients with recurrent ovarian cancer, termed platinum-sensitive and platinum-resistant, according to the best response to first-line platinum-based chemotherapy and consecutive progression free interval (more or less than 6 months) [3; 4]. A large randomized trial (ICON4/AGO-Ovar 2.2) demonstrated the superiority of a combined carboplatin and paclitaxel regimen over platinum monotherapy in platinum-sensitive patients [5]. Today, most of the patients will receive first-line chemotherapy with paclitaxel and a platinum compound, so that the cumulative neurotoxicity of platinum and paclitaxel compromises the retreatment with these agents [6; 7]. Furthermore, many patients prefer to avoid alopecia in this palliative therapeutic setting. Therefore, various study groups are currently exploring other non-taxane containing platinum combinations in order to optimize the therapeutic index for patients with platinum-sensitive recurrent ovarian cancer $[7 ; 8]$.

Pemetrexed is a multi-targeted antifolate inhibitor of thymidylate synthase (TS), dihydrofolate reductase (DHFR), and glycinamide ribonucleotide formyltransferase (GARFT) [9] and is given in combination with vitamin supplementation. It is currently approved for the treatment of malignant pleural mesothelioma and non-small cell lung cancer in conjunction with cisplatin $[10 ; 11]$ and for the second-line monotherapy of non-small cell lung cancer [12]. Various preclinical studies indicate significant activity of pemetrexed against ovarian xenograft tumors and ovarian carcinoma cells $[13,14,15]$. The toxicity profile of pemetrexed 
is generally favorable without severe hematologic or non-hematologic side effects including a very low rate of neurotoxicity and alopecia $[10,11]$. Therefore, pemetrexed is a good candidate for novel platinum-based combination chemotherapy in recurrent ovarian cancer.

Based on these results, a phase I study was initiated to further evaluate the toxicity profile and dose-limiting toxicity of the combination of pemetrexed plus carboplatin in patients with platinum-sensitive recurrent ovarian cancer. 


\section{Patients and methods}

Design

Patients were enrolled at two German centers (Charité: 18 patients, Jena 2 patients). The trial was performed in accordance with the principles of Good Clinical Practice (GCP) and the Declaration of Helsinki. Protocol approval was gained from the institutional review board or the local ethics committee of each participating institution. An independent monitoring institute was responsible for data control.

A prospective, separate phase-I and II was planned to investigate the safety and efficacy of this new chemotherapy combination. As in the study protocol, primary defined individual clinical study reports from the phase I and phase II were planned. Here, we present the data from the dose finding study.

The primary objective of the phase I study was to determine the maximum tolerated dose (MTD) of the combination therapy of pemetrexed and carboplatin when administered to patients with platinum-sensitive recurrent ovarian cancer.

The secondary objectives of this study were:

- to determine the dose limiting toxicities (DLT) of the combination therapy of pemetrexed and carboplatin,

- to determine the quantitative and qualitative toxicities of pemetrexed in combination with carboplatin,

- to determine a recommended dose of the combination therapy of pemetrexed and carboplatin for future phase 2 studies, and

- to document the antitumor activity of pemetrexed and carboplatin in patients with platinum-sensitive recurrent ovarian cancer through tumor response assessment. 


\section{Patients}

Women $\geq 18$ years of age were eligible who had platinum-sensitive recurrent cancer of the ovary, fallopian tube or peritoneum, at least six months after completion of primary standard therapy with surgery and first-line combination therapy with platinum and paclitaxel. Patients were required to have measurable lesions or non-measurable disease as defined by Response Criteria in Solid Tumors (RECIST) [16] or had to be evaluable for CA-125 response evaluation according to the GCIG-criteria [17]. Eastern Cooperative Oncology Group (ECOG) performance status had to be $\leq 2$, patients were required to have normal hematologic, liver and renal function with laboratory parameters within the normal range, including a glomerular filtration rate $\geq 45 \mathrm{ml} / \mathrm{min}$ based on the standard Cockcroft and Gault formula or on measured GFR using an appropriate radio-labeled method (51-CrEDTA or Tc99m-DTPA), serum creatinine levels $\leq 1.5 \mathrm{mg} / \mathrm{dl}$ and an adequate bone marrow function (absolute neutrophil count $[\mathrm{ANC}] \geq 1.5 \times 10^{9} / 1$ and platelets $\left.\geq 100 \times 10^{9} / 1\right)$. Patients suffering from a secondary malignancy or serious concomitant systemic disorders or psychiatric disease were excluded from the study, as were subjects receiving other cytotoxic, immunological, hormonal or targeted therapy. All patients provided written informed consent. Patients were excluded if they had more than 2 previous lines of therapy for ovarian cancer or a serious concomitant systemic disorder that would compromise the ability to complete the study.

\section{Treatment plan}

Intravenous premedication consisting of a 5-HT3-antagonist was administered 15 minutes prior to chemotherapy infusion. Grade 3 or 4 nausea and/or vomiting should be managed with appropriate changes in an anti-emetic regimen and in regard to the discretion of the investigator.

Patients received pemetrexed IV over a 5 to 10 min bolus, followed by carboplatin IV (calculated via Cockcroft-Gault Equation) over 30 to 60 minutes, given every 21 days for 6 
cycles (up to 8 cycles could be administered at the investigators discretion if clinical benefit was expected).

Both study drugs were dissolved in $250 \mathrm{ml}$ of $0.9 \%$ saline. Patients were required to receive oral folic acid, 350-1000 $\mu \mathrm{g}$ daily at least 1 to 2 weeks before cycle 1 until 3 weeks after the last pemetrexed dose and $1000 \mu \mathrm{g}$ vitamin $\mathrm{B}_{12}$ intramuscularly every 9 weeks, starting at least 1 to 2 weeks before cycle 1 , and then every 9 weeks until 3 weeks after the last pemetrexed dose [18]. To prevent skin rash, dexamethasone $4 \mathrm{mg}$ orally (or equivalent) was given twice daily for 3 days, starting on day 1 prior to pemetrexed administration.

Seven dose-levels were defined upfront (Table 1). Patient accrual and dose escalation depended upon the observed pattern of DLTs. According to the protocol, a cohort of 3-6 patients for each dose level had to be enrolled.

If none of the 3 initial patients of a given level experienced a DLT in cycle 1, enrolment proceeded to the next dose level. If 1 of the initial 3 patients of a given level experienced a DLT in cycle 1 , additional patients had to be enrolled up to a maximum of 6 patients at that level. If no more than one patient experienced a DLT in cycle 1, patient enrolment proceeded to the next level. If 2 of the 3 initial patients of a given level experienced a DLT in cycle 1 , that level had to be considered the maximum tolerated dose (MTD). Dose escalation to the next level was not allowed until the last patient of a given dose level (that is, either the third or sixth patient) had completed the entire first cycle.

A 5-HT3-antagonist was given intravenously 15 minutes prior to every chemotherapy cycle. Use of erythropoietin stimulating agents was allowed; however, no primary prophylactic use of granulocyte colony-stimulating factor (G-CSF) was allowed.

Toxicity 
Toxicity was assessed after each cycle, graded according to the NCI-Common Terminology Criteria for Adverse Events (CTCAE) v3.0, August 9, 2006 [19]. The following toxicities, if observed during cycle 1 of treatment, were considered a dose limiting toxicity (DLT):

- CTCAE Grade 4 neutropenia (ANC $\left.<0.5 \times 10^{9} / 1\right)$ lasting $\geq 7$ days,

- febrile neutropenia (ANC $<1.0 \times 10^{9} / 1$, fever $38.5^{\circ} \mathrm{C}$, no clinically or microbiologically documented infection),

- CTCAE Grade 4 thrombocytopenia (platelets $<25.0 \times 10^{9} / 1$ ),

- $\quad$ any grade hemorrhage with CTCAE Grade $\geq 3$ thrombocytopenia $\left(50.0 \times 10^{9} / 1\right)$,

- CTCAE Grade $\geq 3$ non hematologic toxicity (excluding nausea, vomiting, or CTCAE Grade 3 ALT or AST that returned to baseline prior to next treatment),

- treatment delay of more than 1 week due to unresolved Grade 3 or 4 toxicity.

Blood count and blood chemistry were carried out regularly once a week. Subsequent chemotherapy cycles were allowed if the absolute neutrophil count was $>1.5 \times 10^{9} / 1$ and platelet count was $\geq 100 \times 10^{9} / 1$.

Treatment could be postponed up to one week in case of toxicity. Reduction to dose level -1 was required for treatment delays exceeding one week. Protocol treatment was discontinued if the patient required cycle delay longer than one week due to unresolved grade 3 or greater toxicity.

\section{Response}

Patients were assessed before treatment, during treatment and every 3 months after treatment for 2 years, then every 6 months for 3 years. Physical examination, CA-125 (according to the criteria established by Vergote et al. [17]), and radiological evaluation of measurable tumor 
lesions were performed as baseline assessment. Evaluation of response was performed every other cycle (within 7 days) using the same method that was employed at baseline and in any case of suspected progression of disease. Clinical response was determined by physical examination and ultrasound, computer tomography $(\mathrm{CT})$ or magnetic resonance imaging (MRI) scans. Response was measured according to RECIST criteria [16].

\section{Statistical Analysis}

There were 20 patients enrolled in this phase 1 study. This number depended on the dose levels studied in determining the primary endpoint of this study. The primary endpoint, determination of the MTD was not achieved. All secondary endpoints are summarized in tabular form or provided as listings. All confidence intervals for parameters provided were constructed using a two-sided, 5\% significance level. Descriptive statistics were conducted on patient demographics and patient characteristics. All statistical analyses were conducted using SAS Version 8.2 (SAS Institute Inc, Cary, NC, USA) 


\section{Results}

Patient characteristics

From July 2005 to September 2006, 20 patients with platinum sensitive relapse were enrolled. Median age was 57.4 years (range 37.3-75.0 years), 15 patients had primary ovarian cancer and 5 patients primary peritoneal cancer. The median platinum free interval was 26.2 months (range 7.2-124.4 months).

Patient characteristics are displayed in Table 2.

Treatment profile

The treatment profile is summarized in Table 3. The total number of administered cycles was 115 for pemetrexed and 112 for carboplatin. The median number of cycles was 6 for pemetrexed (range 1-8) and 6 for carboplatin (range 1-8). In dose level 1, four patients were treated, three patients in dose level 2, another four patients in dose level 3, three patients in dose level 4 and three patients in dose levels 5 and 6, each.

For pemetrexed, $95.4 \%$ (range $90.0 \%-99.7 \%$ ) of the planned dose intensity (DI) could be administered and 95.4\% (range 87.3-102.8\%) of carboplatin were applied. Detailed dose intensities are listed in Table 4.

\section{Dose reduction}

There were three dose reductions (two at dose level 3 and one at dose level 4) necessary in the 115 cycles of pemetrexed. For carboplatin, there were three dose reductions in 112 cycles (two at dose level 3 and one at dose level 4). There was in one patient a further additional intrapatient dose reduction necessary.

Treatment discontinuation 
No patient required treatment discontinuation due to unacceptable toxicity. Prior to protocol completion, seven patients discontinued treatment (five due to progressive disease, and two due to patient choice).

\section{Dose-limiting toxicity}

We observed only one DLT: in dose level 3: one patient experienced grade 4 neutropenia for 7 days without clinical squeal. No other dose limiting toxicities were observed. There were no treatment related deaths in this phase I study.

Two serious adverse events were observed, but none of them was considered to be related to

study treatment: One patient suffered from gastrointestinal bleeding (at dose level 1). This 60 year-old patient had a diffuse peritoneal carcinomatosis and diffuse liver metastasis. At the time of the gastrointestinal bleeding, the blood parameters were within the normal range with thrombocytes of $193 / \mathrm{nl}$ and $\mathrm{Hb}$ of $10.5 \mathrm{~g} / \mathrm{dl}$. The bleeding was managed conservatively. The second patient suffered from subileus (at dose level 6). This event was managed conservatively and was considered to be related to the underlying diffuse peritoneal carcinomatosis and not due to the study drug itself. Five patients required dose reduction due to toxicity.

\section{Haematological toxicity}

No neutropenic fever, sepsis or chemotherapy-related deaths occurred during the trial. Overall, haematological side effects were manageable and without sequelae. Grade 4 neutropenia occurred in one patient in dose level 3. No other grade 4 hematologic toxicities were observed, Details are listed in Table 5.

A prophylactic treatment with Erythropoietin was permitted, but in no patient erythropoietin was administered. 


\section{Non-hematological toxicity}

Non-hematological side effects were mild and rarely greater than grade 2 . Three patients suffered from grade 3 toxicity: 1 patient with nausea (dose level 3), 1 patient with dyspnea (dose level 4) and 1 patient with allergic reaction to carboplatin (dose level 1). No grade 4 non-hematological side effects occurred. Patients did not experience neurotoxicity higher than grade 2. Seven patients suffered from grade 1 and one patient from grade 2 neurotoxicity, both were attributed to the previous chemotherapy with carboplatin and paclitaxel. Grade 1 alopecia was observed in six patients. Allergic reaction to carboplatin occurred in five patients with grade 1 and in one patient with grade 3. Seventeen patients experienced grade 1 or 2 nausea, 14 grades 1 or 2 vomiting. Grade 1 diarrhea occurred in 5 patients. No unexpected non-hematological toxicity was observed; details are listed in Table 6.

\section{Response and survival}

Nineteen patients could be assessed for response, of which 17 were analyzed according to the CA-125 response criteria; two patients were analyzed by RECIST criteria. Twelve patients achieved complete remission $(63.2 \%, 95 \%$ CI: 41.5-84.9), four patients achieved partial response $(21.1 \%, 95 \%$ CI: $2.8-39.4 \%)$, one patient had stable disease $(5.3 \%, 95 \%$ CI: 0$15.3 \%)$ and two patients had progressive disease (10.5\%, 95\% CI: 0-24.3\%). By intent-to-treat, the response rate was estimated to be $80 \%$ (95\% CI: 62.5-97.5\%). The median follow-up was 9.8 months (95\% CI 6.2-14 months). At the time of final data analysis, 18 of the 20 enrolled patients had progressive disease, 17 patients were alive. 


\section{Discussion}

Platinum-based combination therapy with paclitaxel or gemcitabine is currently considered to be the standard second-line treatment for patients with platinum-sensitive relapsed ovarian cancer $[5,7]$. The incidence of neurotoxicity in patients receiving conventional paclitaxel and carboplatin as first-line treatment was estimated to be $54 \%$ of all patients [6], while approximately $13 \%$ suffer from grade 2 to 3 neurotoxicity. In a large phase-III trial of the ICON-AGO intergroup evaluating treatment with carboplatin and paclitaxel as second-line therapy, a significantly higher incidence of grade 2 to 4 neurotoxicity (20\%) was observed in comparison with single agent platinum (1\%) [5]. This observation is notable, especially because in this trial, only $43 \%$ of the patients had received platinum- and taxane-based combination chemotherapy during first-line therapy. Since at the present time most patients will be treated with carboplatin and paclitaxel as first-line therapy, the incidence of neurotoxicity will probably be significantly higher and consequently might have substantial impact on the quality of life of these patients.

Thus, in a situation where cure is generally not achieved, there is high clinical need for alternative platinum-based combinations to improve the therapeutic index with special attention to patients' quality of life. Pemetrexed seems to be an attractive candidate for a platinum combination. It has proven activity in mesothelioma and non-small cell lung cancer, and neurotoxicity is rare $[10,11,12]$. In the present study, eight patients suffered from neurotoxicity, which pre-existed from prior taxane-based first-line chemotherapy and was not attributed to pemetrexed.

To our knowledge, this is the first dose escalating study of the combination pemetrexed and carboplatin in ovarian cancer. We observed only one DLT: in dose level 3, one patient experienced grade 4 neutropenia for 7 days without clinical squeal. Despite the fact that we applied pemetrexed up to a dose of $900 \mathrm{mg} / \mathrm{m}^{2}$ and carboplatin up to an AUC of 6 we did not reach the maximum tolerated dose. Matulonis et al. combined pemetrexed at $500 \mathrm{mg} / \mathrm{m}^{2}$ and carboplatin at AUC 5 in a phase-II study [20]. Grade 3 and 4 hematologic toxicities included neutropenia (41\%), thrombocytopenia (23\%), and anemia (9\%). In their study, the response rate was $51.1 \%$ (95\% CI: 35.8-66.3\%) without any patients achieving a complete response. Despite the methodical limitation of cross-trial comparison, response rate was substantially 
higher in the current trial (80\%) with 12 patients achieving CR. In contrast to our study, the study by Matulonis included more than $50 \%$ of patients with more than two prior chemotherapies.

These differences in the inclusion criteria or a potentially effect of the different applied dose may explain the different toxicity profiles and response rates of both trials. Another explanation might be the difference in response evaluation, as Matulonis et al. used RECIST criteria in contrast to GCIG CA-125 criteria utilized in the current trial.

Regarding vitamin supplementation, the current trial is to our knowledge also the first dose escalating study of the combination of pemetrexed and carboplatin. Until today, one phase-I study with pemetrexed and carboplatin in 27 patients with malignant pleural mesothelioma has been conducted, but this study was near completion when supplementation with folic acid and vitamin $B_{12}$ was instituted; therefore, these patients were not supplemented. The MTD for pemetrexed was $500 \mathrm{mg} / \mathrm{m}^{2}$ and for carboplatin AUC 6 and was defined by two episodes of grade 4 neutropenia (data on file). Vitamin $B_{12}$ supplementation causes a statistically significant reduction in plasma homocysteine concentrations over time and a significant reduction in the frequencies of severe hematologic toxicities and non-hematological toxicities in patients receiving pemetrexed therapy [21]. In contrast to the phase-I study in mesothelioma, in the present study all patients received vitamins. This might be an explanation for the improved dose tolerance we observed.

Despite the favorable hematological and non-hematological toxicity profile in the present study, the optimal dose of pemetrexed in a combination with carboplatin is not yet defined. Recently, Vergote et al. presented the results of a randomized study comparing pemetrexed $500 \mathrm{mg} / \mathrm{m}^{2}$ with $900 \mathrm{mg} / \mathrm{m}^{2}$ in patients with platinum-resistant ovarian cancer [22]. There were no differences in response rate or clinical outcome, but the lower dose had a significantly better toxicity profile. 
Additionally, there is now growing evidence that doses higher than the currently approved $500 \mathrm{mg} / \mathrm{m}^{2}$ of pemetrexed do not improve the efficacy in several tumor types including ovarian, breast and non-small cell lung cancer [23, 24, 25].

Despite the fact that it is unclear whether or not these results can be translated into the platinum-pemetrexed combination, it is very unlikely that a higher dose of pemetrexed could yield a higher efficacy.

Nevertheless it can be criticized that in the present study further dose escalation were may possible because the MTD was not reached. But it should be mentioned that different study groups $[7,26]$ demonstrated the efficacy of specific carboplatin-based combinations such as pegylated doxorubin/carboplatin or gemcitabine/carboplatin without using the highest possible dosages and there is no evidence showing a clear effect of the dose on progression free survival or overall survival in relapsed ovarian cancer.

Therefore the committee of the present study has decided to use - for the subsequent phase-II trial - a dose of $500 \mathrm{mg} / \mathrm{m}^{2}$ for pemetrexed in combination with carboplatin according AUC 6.

The primary objective of this study is to define the clinical response rate; secondary objectives are the identification of acute and late toxicities as well as the time up to progression and overall survival. Furthermore, various potential biomarkers will be explored in the phase-II trial. It is only when validated biochemical response markers are available, that patients who will benefit from this new agent can be identified [27].

\section{Acknowledgements}

We wish to thank all participating nurses and patients. Without their enthusiastic collaboration, this work would not have been possible.

\section{Conflict of interest}


Thomas Bauknecht and Katherine Look are employees of Eli Lilly and Company. For all other authors there is no conflict of interest involved with the data presented here. 


\section{References}

1. Jemal A, Siegel R, Ward E et al (2007) Cancer statistics, 2007. CA Cancer J Clin 57:43-66.

2. Ozols RF, Bookman MA, Connolly DC et al (2004) Focus on epithelial ovarian cancer. Cancer Cell 5:19-24.

3. Markmann M, Rothman R, Hakes T et al (1991) Second-line platinum therapy in patients with ovarian cancer previously treated with cisplatin. J Clin Oncol 9:389-393.

4. Gore ME, Fryatt I, Wiltshaw E, Dawson T (1990) Treatment of relapsed carcinoma of the ovary with cisplatin or carboplatin following initial treatment with these compounds. Gynecol Oncol 36:207-211.

5. Parmar MK, Ledermann JA, Colombo N et al (2003) Paclitaxel plus platinum-based chemotherapy versus conventional platinum-based chemotherapy in women with relapsed ovarian cancer: the ICON4/AGO-OVAR-2.2 trial. Lancet 361:2099-106.

6. Pignata S, De Placido S, Biamonte R et al (2006) Residual neurotoxicity in ovarian cancer patients in clinical remission after first-line chemotherapy with carboplatin and paclitaxel: The Multicenter Italian Trial in Ovarian cancer (MITO-4) retrospective study. BMC Cancer 6:5.

7. Pfisterer J, Plante M, Vergote I et al (2006) Gemcitabine plus carboplatin compared with carboplatin in patients with platinum-sensitive recurrent ovarian cancer: an intergroup trial of the AGO-OVAR, the NCIC CTG, and the EORTC GCG. J Clin Oncol 24:4699-4707.

8. Ferrero JM, Weber B, Geay JF et al (2007) Second-line chemotherapy with pegylated liposomal doxorubicin and carboplatin is highly effective in patients with advanced ovarian cancer in late relapse: a GINECO phase II trial.

Ann Oncol 18:263-8.

9. Shih C, Chen VJ, Gates SB et al (1997) LY231514 a pyrrolo[2,3-d] pyrimidine base antifolate that inhibits multiple folate requiring enzyames. Ca Res 57:1116-23.

10. Vogelzang NJ, Rusthoven JJ, Symanowski J et al (2003) Phase III study of pemetrexed in combination with cisplatin versus cisplatin alone in patients with malignant pleural mesothelioma. J Clin Oncol 21: 2636-2644.

11. Scagliotti GV, Parikh P, von Pawel J et al (2008) Phase III study comparing cisplatin plus gemcitabine with cisplatin plus pemetrexed in chemotherapy-naive patients with advanced-stage non-small-cell lung cancer. J Clin Oncol 26:3543-51. 
12. Hanna N, Shepherd FA, Fossella FV et al (2004) Randomized phase III trial of pemetrexed versus docetaxel in patients with non-small-cell lung cancer previously treated with chemotherapy. J Clin Oncol 22: 1589-1597.

13. Miotti S, Bagnoli M, Ottone F et al (1997) Simultaneous activity of two different mechanisms of folate transport in ovarian carcinoma cell lines. J Cell Biochem 65:479491.

14. Corona G, Giannini F, Fabris M et al (1998) Role of folate receptor and reduced folate carrier in the transport of 5-methyltetrahydrofolic acid in human ovarian carcinoma cells. Int J Cancer 75:125-133.

15. Takimoto CH, Hammond-Thelin LA, Latz JE et al (2007) Phase I and pharmacokinetic study of pemetrexed with high-dose folic acid supplementation or multivitamin supplementation in patients with locally advanced or metastatic cancer. Clin Cancer Res 13:2675-2683.

16. Therasse P, Arbuck SG, Eisenhauer EA et al (2000) New guidelines to evaluate the response to treatment in solid tumors. J Natl Cancer Inst 92:205-16.

17. Vergote I, Rustin GJ, Eisenhauer EA et al (2000) Re: new guidelines to evaluate the response to treatment in solid tumors [ovarian cancer]. Gynecologic Cancer Intergroup. J Natl Cancer Inst 92:1534-1535.

18. Chattopadhyay S, Tamari R, Min SH et al (2009)Commentary: A Case for Minimizing Folate Supplementation in Clinical Regimens with Pemetrexed Based on the Marked Sensitivity of the Drug to Folate Availability. The Oncologist October 2009.

19. National Cancer Institute: Cancer Therapy Evaluation Program: Common Terminology Criteria for Adverse Events v3.0 (CTCAE). http://ctep.cancer.gov/reporting/ctc_v30.html

20. Matulonis UA, Horowitz NS, Campos SM et al (2008). Phase II Study of Carboplatin and Pemetrexed for the Treatment of Platinum-Sensitive Recurrent Ovarian Cancer.J Clin Oncol 10. [Epub ahead of print].

21. Niyikiza C, Baker SD, Seitz DE et al (2002) Homocysteine and methylmalonic acid: markers to predict and avoid toxicity from pemetrexed therapy. Mol Cancer Ther 1:54552.

22. Vergote I, Calvert H, Kania M et al (2009) A Randomized, Double-Blind, Phase 2 Study of Two Doses of Pemetrexed in the Treatment of Platinum-Resistant, Epithelial Ovarian or Primary Peritoneal Cancer. Eur J Cancer. 23. [Epub ahead of print]. 
23. Cullen MH, Zatloukal P, Sörenson S et al (2008) A randomized phase III trial comparing standard and high-dose pemetrexed as second-line treatment in patients with locally advanced or metastatic non-small-cell lung cancer. Ann Oncol 19: 939-945.

24. Llombart-Cussac A, Martin M, Harbeck N et al (2007) A randomized, double-blind, phase II study of two doses of pemetrexed as first-line chemotherapy for advanced breast cancer. Clin Cancer Res 13: 3652-3659.

25. Ohe Y, Ichinose Y, Nakagawa K et al (2008) Efficacy and safety of two doses of pemetrexed supplemented with folic acid and vitamin B12 in previously treated patients with non-small cell lung cancer. Clin Cancer Res 14: 4206-4212.

26. Pujade-Lauraine E, Mahner S, Kaern J et al (2009), A randomized, phase III study of carboplatin and pegylated liposomal doxorubicin versus carboplatin and paclitaxel in relapsed platinum-sensitive ovarian cancer (OC): CALYPSO study of the Gynecologic Cancer Intergroup (GCIG).J Clin Oncol 27:18s, 2009 (suppl; abstr LBA5509).

27. Lederman JA, Stebbing J (2009) Positioning pemetrexed in the treatment of ovarian cancer. Eur J Cancer 2009. 
Tables

Table 1: Dose levels of the study

$\begin{array}{lll}\text { Level } & \text { Pemetrexed } & \text { Carboplatin } \\ -1 & 400 \mathrm{mg} / \mathrm{m}^{2} & \text { AUC 5 } \\ 1 & 500 \mathrm{mg} / \mathrm{m}^{2} & \text { AUC } 5 \\ 2 & 600 \mathrm{mg} / \mathrm{m}^{2} & \text { AUC } 5 \\ 3 & 600 \mathrm{mg} / \mathrm{m}^{2} & \text { AUC 6 } \\ 4 & 700 \mathrm{mg} / \mathrm{m}^{2} & \text { AUC } 6 \\ 5 & 800 \mathrm{mg} / \mathrm{m}^{2} & \text { AUC } 6 \\ 6 & 900 \mathrm{mg} / \mathrm{m}^{2} & \text { AUC } 6\end{array}$

Table 2: Baseline patient characteristics $(n=20)$

Median age, years (range)

ECOG performance status

FIGO stage at primary diagnosis

$\begin{array}{lll} & & 57.4(37.3-75) \\ \text { 0 } & & 3 \\ \text { I } & & 17 \\ & \text { I } & 1 \\ \text { II } & 1 \\ \text { III } & 16 \\ \text { IV } & 2\end{array}$

Median platinum free interval, months (range) $\quad 26.2(7.2-124.4)$

Table 3: Treatment profile

$\begin{array}{llllll}\begin{array}{l}\text { Dose } \\ \text { Level }\end{array} & \begin{array}{l}\text { Number of } \\ \text { Patients }\end{array} & \begin{array}{l}\text { Pemetrexed } \\ \text { Median Cycles } \\ \text { (Range) }\end{array} & \begin{array}{l}\text { Total } \\ \text { Cycles }\end{array} & \begin{array}{l}\text { Carboplatin } \\ \text { Median Cycles } \\ \text { (Range) }\end{array} & \begin{array}{l}\text { Total } \\ \text { Cycles }\end{array} \\ \mathbf{1} & 4 & 6(6-8) & 26 & 6(3-8) & 26 \\ \mathbf{2} & 3 & 8(6-8) & 22 & 8(6-8) & 22 \\ \mathbf{3} & 4 & 6(1-6) & 19 & 6(1-6) & 19 \\ \mathbf{4} & 3 & 6(6-6) & 18 & 6(2-6) & 15 \\ \mathbf{5} & 3 & 6(6-7) & 19 & 6(6-7) & 19 \\ \mathbf{6} & 3 & 4(1-6) & 11 & 3(1-6) & 11\end{array}$

Total 20

115

112 
Table 4: Dose intensity

$\begin{array}{cllll}\text { Treatment } & \text { Dose Level } & \begin{array}{l}\text { Planned } \\ \text { weekly } \\ \text { (mean/patient) }\end{array} & \begin{array}{l}\text { Delivered weekly } \\ \text { (mean/patient) }\end{array} & \begin{array}{l}\text { \% of planned DI } \\ \text { (delivered/planned) }\end{array} \\ \text { Pemetrexed } & 1 & \begin{array}{l}166.7 \mathrm{mg} / \mathrm{m}^{2} \\ \end{array} & 157.0 \mathrm{mg} / \mathrm{m}^{2} & 94.2 \\ & 2 & 200.0 \mathrm{mg} / \mathrm{m}^{2} & 196.5 \mathrm{mg} / \mathrm{m}^{2} & 98.2 \\ & 3 & 200.0 \mathrm{mg} / \mathrm{m}^{2} & 180.1 \mathrm{mg} / \mathrm{m}^{2} & 90.0 \\ & 4 & 233.3 \mathrm{mg} / \mathrm{m}^{2} & 218.2 \mathrm{mg} / \mathrm{m}^{2} & 93.5 \\ & 5 & 266.7 \mathrm{mg} / \mathrm{m}^{2} & 262.7 \mathrm{mg} / \mathrm{m}^{2} & 98.5 \\ & 6 & 300.0 \mathrm{mg} / \mathrm{m}^{2} & 299.2 \mathrm{mg} / \mathrm{m}^{2} & 99.7 \\ & & & & \\ \text { Carboplatin } & & \text { AUC } 1.7 & \text { AUC } 1.5 & 91.8 \\ & 2 & \text { AUC } 1.8 & \text { AUC } 1.6 & 96.6 \\ & 3 & \text { AUC } 2.0 & \text { AUC } 1.8 & 87.3 \\ & 4 & \text { AUC } 2.0 & \text { AUC } 1.9 & 93.3 \\ & 5 & \text { AUC } 2.0 & \text { AUC } 2.0 & 100.6 \\ & 6 & \text { AUC } 2.0 & \text { AUC } 2.1 & 102.8\end{array}$

Table 5: Hematological toxicity (CTC-Grade I-IV)

\begin{tabular}{llllll} 
& \multicolumn{3}{l}{ Maximum CTCAE } & & \multicolumn{1}{c}{ Total I- } \\
& grade & & & IV \\
CTCAE Toxicity & I & II & III & IV & \\
Hemoglobin & 3 & 3 & & & 6 \\
Leukocytes (WBC) & 4 & 2 & 1 & & 7 \\
Neutrophils (ANC) & 2 & 1 & 4 & 1 & 8 \\
Platelets & 7 & 2 & 2 & & 11
\end{tabular}

Table 6: Non-hematological toxicity (CTC-Grade I-IV)

\begin{tabular}{llllll} 
& \multicolumn{2}{l}{$\begin{array}{l}\text { Maximum CTCAE } \\
\text { grade }\end{array}$} & & & Total \\
CTCAE Toxicity & I & II & III & IV & \\
Allergic reaction & 5 & - & 1 & - & 6 \\
Alopecia & 6 & - & - & - & 6 \\
Constipation & 9 & 5 & - & - & 14 \\
Diarrhea & 5 & - & - & - & 5 \\
Dyspnea & 1 & - & 1 & - & 2 \\
Fatigue & 7 & 7 & - & - & 14 \\
Fever & 1 & - & - & - & 1 \\
Flushing & 7 & 2 & - & - & 9 \\
Mucositis & 6 & 2 & - & - & 8 \\
Nausea & 10 & 7 & 1 & - & 18 \\
Neuropathy (sensory) & 7 & 1 & - & - & 8 \\
Pruritus & 2 & - & - & - & 2 \\
Vomiting & 9 & 5 & - & - & 14
\end{tabular}

